\title{
Exploring the Impact of Students' Learning Approach on Collaborative Group Modeling of Blood Circulation
}

\author{
Shinyoung Lee $\cdot$ Eunhee Kang $\cdot$ Heui-Baik Kim
}

Published online: 10 August 2014

(c) The Author(s) 2014. This article is published with open access at Springerlink.com

\begin{abstract}
This study aimed to explore the effect on group dynamics of statements associated with deep learning approaches (DLA) and their contribution to cognitive collaboration and model development during group modeling of blood circulation. A group was selected for an in-depth analysis of collaborative group modeling. This group constructed a model in a similar fashion to a target model and demonstrated within-group dialogic interaction patterns. It was found that statements associated with DLA contributed to the collaborative group dynamics by providing cognitive scaffolding and enabling critical monitoring, which together facilitated model development and students' participation and understanding. In the model generation phase, the skills demonstrated indicated the use of statements associated with DLA as one student focused on the principles of blood circulation, thereby providing scaffolding for the other students. These students then generated another sub-model. In the model elaboration phase, statements associated with DLA elements such as request information of mechanism (AQ-a) and resolve discrepancies in knowledge (AQ-b) provided students with metacognitive scaffolding and enabled them to show their
\end{abstract}

\section{S. Lee}

Division of College Scholastic Ability Test, Korea Institute for Curriculum and Evaluation, 21-15, Jeongdong-gil, Jung-gu,

Seoul 100-784, Korea

e-mail: vivimoon1@kice.re.kr

E. Kang · H.-B. Kim $(\square)$

Department of Biology Education, College of Education, Seoul National University, San 56-1, Sillim 9(gu)-dong, Gwanak-gu, Seoul 151-748, Korea

e-mail: hbkim56@snu.ac.kr

E. Kang

e-mail: chukbai@snu.ac.kr deep cognitive participation. Moreover, statements associated with DLA elements such as asking questions or metacognitive activity enabled the students to monitor others' models or ideas critically, showing that active cognitive interaction was taking place within the group. These findings reveal that individual learning approaches will bring a synergistic effect to a group modeling process and can lead to practical educational insights for educators seeking to use lessons based on group modeling.

Keywords Deep learning approach · Group modeling · Cognitive collaboration - Blood circulation

\section{Introduction}

Modeling - the process of constructing models-is a key process for scientists in the development of scientific ideas. Scientists simplify complex phenomena through modeling and the development of corresponding explanations (Giere 1999; Gilbert et al. 2000; Morrison and Morgan 1999; Nersessian 1999). In recent years, modeling has received considerable attention as a useful educational tool in the science classroom (Schwarz et al. 2009). In the context of learning science, a model is an explanatory system that represents objects or phenomena via discourse, writing, behavior, and drawing (Harrison and Treagust 2000; Passmore and Stewart 2002; Schwarz and White 2005), while modeling is the process of generating, evaluating, and modifying models in order to create models that closely represent the scientific concepts (Justi and Gilbert 2002; Rea-Ramirez et al. 2008). Both models and modeling play an important role in developing students' understanding of certain phenomena or information as they construct and represent their mental models. Students 
generate and test models that enable them to experience epistemic practices through both empirical and thought experiments in the science classroom (Gilbert et al. 2000).

In practice, students are provided with scientists' models to serve as simple illustrations; however, they generally receive little time for exploring the evidence of the models, or for constructing their own explanatory models of the phenomena (Lehrer and Schauble 2012; Windschitl et al. 2008). Accordingly, students frequently cannot see the value of the models explaining the phenomena, and they fail to see the differences between the scientific models and the actual phenomena (Krajcik and Merritt 2012). Consequently, it has been acknowledged that modeling practices should be encouraged cumulatively and systemically, as opposed to being imparted as if they were a matter of course in which the evidence is completely defined without being open to question or argument (Lehrer and Schauble 2012; Windschitl et al. 2008).

Clement (2008) suggested the co-construction of models in a group modeling context as a way to overcome the problems surrounding model-based learning. Group modeling allows students to experience the epistemic practice through modeling in the science classroom. In this study, we regard group modeling as a method of social learning from the sociocognitive perspective-that is, students learn through the metacognition and information processing that occurs during social interaction (Oliveira and Sadler 2008). We assume that group members are able to collaborate in the process of co-constructing the group models, which together make up the group goal, and that the group models constructed collaboratively by group members can be internalized by individual students, and contribute to the formation of the individual student's mental models. Following this assumption, the context of each group (such as individual students' learning orientation and group norms) can influence their social interaction and eventually be reflected in the process of group model development.

During group modeling, various group contexts can be created, depending on the members of the group, since each grouping of students will include individuals with different cognitive abilities, learning approaches, academic achievements, epistemology, and affective attitudes toward science (Kyza et al. 2011). Among those factors, learning approaches will be revealed through students' statements and these can be a critical element in determining the success of group learning in the science classroom (Chin and Brown 2000). Learning approach refers to the students' tendencies or attitudes as he or she solves learning tasks, and whether he or she attempts to understand associated concepts and relationships (Entwistle 1981). Specifically, students who use deep learning approaches tend to be motivated by an inner interest or by an intrinsic motivation, and they apply in-depth strategies that connect their prior knowledge to the learning materials (Biggs 1993). A process of cognitive reasoning through metacognition, which is one of the features of deep learning, is critical for successful group modeling (Lee and Kim 2014; Mendonça and Justi 2013). Therefore, students who adopt deep learning approaches may play an important role during the modeling process, because a student who has perfected a deep learning approach has generally also developed fairly strong metacognitive competency (Case and Gunstone 2002).

Several researchers have stressed that students' learning approaches can have positive effects on the individual's conceptual changes and academic achievements (BouJaoude 1992; Cavallo and Schafer 1994; Stewart and Dale 1989). However, little research has been conducted to explore how an individual student's learning approach affects group learning processes. Students who use deep learning approaches place emphasis on explanation, and on the generation of spontaneous thinking, attempting to evaluate and control their learning processes through reflective thinking (Chin and Brown 2000). Hence, it is possible that small-group modeling will be influenced by cognitive interactions among students who have different learning approaches. In particular, students who adopt deep learning approaches may play an important role in the collaborative learning process.

This study assumes that learning approaches can be crucial, both for individual learning and in group learning processes, and we therefore focused on a group whose created model was close to the target model, and whose dialogic interaction patterns were identified. During the course of the group modeling activities, through an analysis of their discourse, we investigated the group members' collaborative cognitive processes and positive cognitive participation to ascertain how they were affected by statements associated with deep learning approaches (DLA). Referring to the definition of collaboration given by Roschelle and Teasley (1995), we define cognitive collaboration as a process in which individual students provide cognitive support to one another continuously during learning in order to achieve the group's set goals.

In order to explore cognitive collaboration in group modeling, participants were provided with specially designed modeling tasks involving blood circulation. Since the concept of blood circulation is difficult for students to experience or observe directly, it is easy for students to misunderstand it (Buckley 2000; Chi 2005). Students need to have comprehensive thinking skills in order to understand the interaction between the functions of the elements in the circulatory system, and their structures at the cellular, organ, and organ system levels. Therefore, this topic was seen as appropriate for a group of students of varying abilities, as this would encourage students to work together 
through collaborative group modeling. The students were required to construct group models related to blood circulation through participation in hands-on activities, which had the potential to induce students to participate spontaneously in the cognitive process of group modeling. We examined the following research questions by conducting a case study with one group in which the students were required to collaborate with the other group members in a cognitively productive and fruitful manner.

The questions guiding the research were as follows:

1. What effect do statements associated with deep learning approaches have on group dynamics during the group modeling process?

2. How do group dynamics contribute to cognitive collaboration and model development?

\section{Theoretical Framework}

\section{Collaborative Reasoning in Group Modeling of Science}

Researchers employ various definitions of models, including the following: "simplified representations for explaining and predicting phenomena" (Harrison and Treagust 2000; Passmore and Stewart 2002; Schwarz et al. 2009); "consensus models based on scientific theories" (Clement 2008; Treagust et al. 2002); "links between abstract theories and specific experiments" (Gilbert et al. 2000). Although definitions of models vary from author to author, one thing they have in common is that they define models as explanatory representations of natural phenomena, or of systems, using objects, language, behaviors, writing, and drawings. In this study, this last definition of a model is used so that the common ground of all the previously mentioned definitions is covered and modeling is defined as the development process of generating, evaluating, and modifying models (Harrison and Treagust 2000; Justi and Gilbert 2002; Rea-Ramirez et al. 2008; Schwarz and White 2005).

Modeling is therefore considered to be a practice that enables students to experience the scientists' work in the science classroom, and which has recently been widely applied to science education reform. As modeling reflects the generation, evaluation, and communication processes of scientific knowledge, it can be viewed as a scientific practice by means of which students can experience social interactions through using language (Duschl et al. 2007). In this regard, Next Generation Science Standards (NGSS) in the USA introduced a major practice that helps students develop and use models to learn core ideas (Achieve, Inc. 2013). To elaborate on the earlier definitions, modeling is the process of explaining the relationships between systems, or elements of a system, based on empirical and conceptual evidence (Böttcher and Meisert 2011; Mendonça and Justi 2013; Passmore and Svoboda 2012; Svoboda and Passmore 2013). Hence, when students engage in modeling in science lessons, they do not just describe empirical experiences, as they would with experiments and observations; they can also reason, explain, and communicate phenomena or systems using empirical experiences as evidence.

The evidence yielded by empirical experiences is not just used for generating models. Models can be elaborated by several people's participation in the evidence-based reasoning process. The model strengthened by reasoning enhanced the explanatory power of the phenomena (ReaRamirez et al. 2008). Models created by scientists are evaluated, modified, and elaborated through argumentative interactions until they are accepted by peer scientists. Likewise, students also need to interact with each other to reach the goals of sense-making, engaging in the articulation of their thought, and using methods of persuasive reasoning to explain the specific phenomenon (Berland and Reiser 2009). According to Berland and Reiser (2009), these three discourse goals may be elaborated as follows: Students explain phenomena by connecting evidence and assertions, and this can be viewed as sense-making; articulating refers to the expression or communication that explains the phenomena; and persuading is a social process, since it considers the validity of various ideas, delivered by many people, in order to find the most appropriate explanation. These three goals of scientific practice-sense-making, articulating, and persuading - can create the context of argumentation and can also illustrate the appropriateness of the social process in modeling.

In argumentative discussion during modeling, students can generate evidence-based models through sense-making, while articulation and persuasion allow for argumentative interaction around an evaluation of the strengths and weaknesses of the models or ideas generated by the group (Passmore and Svoboda 2012). As they can experience small-group argumentation in which they connect claims and evidence through that reasoning (Driver et al. 2000; Jiménez-Aleixandre and Erduran 2008), small-group modeling can be viewed as a type of reasoning in which students justify their models and criticize others' ideas based on appropriate reasons. Therefore, as an interactive reasoning process, small-group modeling can be considered a form of science learning that enables cognitive collaboration. Particularly in cases where group members have diverse knowledge bases, small-group modeling affords the opportunity for members to collaborate cognitively by acting as scaffolding for each other and monitoring each other's opinions critically (Oliveira and Sadler 2008). 
It is important to note that all these types of modeling features should be reflected in school science; however, it is mainly teachers who lead the cognitive reasoning process when students engage in small-group modeling activities. Cognitive collaboration in modeling has been explored only between teachers and students - that is, the teacher provides question prompts and clues containing scientific knowledge and critically evaluates students' models (Mendonça and Justi 2013; Núñez-Oveido et al. 2008; Passmore and Svoboda 2012). However, while students do sometimes need help from teachers when in difficulty, some groups may try to construct their models through interaction between group members, with little help from the teacher. Students who engage in cognitive collaboration with group members can be seen as the ones who actually engage in small-group modeling, and these are the students who eventually have authentic cognitive experiences (Lee and Kim 2014).

\section{An Approach to Learning Science through Collaborative Modeling}

Some students are better at learning that requires deep understanding of scientific concepts because they improve their ability to learn through experiencing different practices. A number of researchers have tried to investigate practices in the learning process in terms of individual characteristics, and especially learning approaches, with a view to explaining the variable levels of academic achievement among students (Biggs 1993; Cano 2005; Case and Gunstone 2002; Chiou et al. 2012, 2013; Entwistle 1981; Säljö 1979). Although researchers have proposed many different types of learning approach, a differentiation between deep and surface learning approaches is the most common (Biggs 1993; Entwistle 1981; Case and Gunstone 2002; Chin and Brown 2000). The features that distinguish these two approaches are learning motivation and learning strategies (Biggs 1993). Students with a surface approach to learning are motivated by fear of failure, and tend to focus on rote learning, while students using a deep approach to learning are more likely to be motivated by an intrinsic interest in learning about the topic, prompting them to try to connect with prior knowledge and maximize meaning (Biggs 1993). This process can lead to a meaningful reception of learning (Biggs 1993). The differences in learning approach explain why students demonstrate variable learning outcomes, in spite of having the same prior knowledge.

Most research into learning approaches has focused on how to distinguish domain-general learning approaches, and the researchers have tried to understand the relationship between a particular learning approach and the learning outcome (Entwistle and Ramsden 1983; Biggs
1993). However, each discipline may involve a different epistemological process because researchers in different domains experience different cognitive processes in their work. Consequently, students' surface and deep learning approaches would manifest differently according to the particular discipline (Ramsden 1992), so it is not enough to explain students' science learning processes and outcomes using only domain-general approaches. More recently, research has been undertaken to explore students' learning approaches in the context of science learning in the field of science education (Chiou et al. 2012, 2013; Lee et al. 2008; Chin and Brown 2000). For example, Lee et al. (2008) developed a questionnaire that provides a domain-specific approach, and they claimed that a relationship exists between the learning approach and scientific epistemology. In two studies carried out by Chiou et al. (2012, 2013), learning approaches were explored in terms of how they relate to the more specific scientific domains of physics and biology. One common limitation of these studies is that they applied only a quantitative approach to exploring the relationship between conceptions of learning science and learning approaches. In other words, they did not identify the educational significance in the context of the real-life science classroom.

Unlike the research just mentioned, Chin and Brown (2000) conducted a qualitative analysis of the learning strategies students used during a hands-on investigation. In their paper, the distinctions between deep and surface learning approaches were classified into five categories: generative thinking, the nature of explanations, asking questions, metacognitive activity, and approaches to tasks. Students who adopted a deep learning approach generated their ideas more spontaneously, focused on explaining the mechanism of the scientific phenomena, asked questions to request information concerning the mechanism, and evaluated ideas or opinions through reflective thinking. They also persisted in following up on an idea with some sustained interest before moving on to another one. Ultimately, Chin and Brown (2000) conducted a meaningful qualitative analysis of students' science learning approaches in an authentic context, and their resulting classification involves domain-specific learning approaches. Hence, the features of the learning approaches presented in their study can be used as a measuring tool to provide more essential explanations about students' science learning.

This study aimed to identify the cognitive reasoning processes happening during science lessons as a result of small-group modeling tasks and adopts the features analyzed by Chin and Brown (2000) as the framework for a study on statements associated with a deep learning approach. The assumption is that deep learning approaches have cognitive and epistemic significance in the modeling process. In addition, modeling practice is expected to 
provide an additional benefit by taking on the role of explaining, as a cognitive strategy (Odenbaugh 2005). When scientists construct models by organizing and articulating their ideas, they adopt prior knowledge; their reasoning is based on comparison and metaphor; visual representations are generated; and empirical or thought experiments are performed to prove their ideas (Svoboda and Passmore 2013). The features of scientific practice that emerge during the modeling process are similar to those features that were revealed as students engaged in the deep learning process in Chin and Brown's study. We assume that the features of a deep learning approach may be critical in order to achieve successful learning through modeling.

However, Chin and Brown only focused on individual features in the learning approaches and did not identify the synergistic effects of interaction between peer students. They noted that the degree of metacognition and information processing displayed by individual students differed depending on the particular student's beliefs about learning in terms of epistemology. Therefore, we believe that a study focusing both on learning approaches and cognitive collaboration in group modeling will have meaningful implications for science education from the sociocognitive perspective.

Meanwhile, the five features of the deep learning approach identified relate to the epistemic features of model-based inquiry. These features can be elucidated as the generation of thinking, explanations about mechanism of the scientific phenomena, asking questions, metacognitive thinking, and approaches to tasks. Windschitl et al. (2008) insisted that the epistemic features of scientific knowledge must be testable, revisable, explanatory, conjectural, and generative and that these are all embodied in modeling-based inquiry. These features can be revealed, together with deep learning approaches, in each modeling phase. Students' statements associated with the generating of explanations and asking questions about the mechanisms of the phenomena can facilitate explanatory and conjectural epistemic practice during the model generation phase, while students' statements associated with metacognitive activity can shape testable and revisable epistemic practice during the model evaluation and modification phases, and influence generative epistemic practice in the model application phase.

These epistemic practices in the modeling process can be viewed as a cognitive reasoning process triggered by argumentation interactions (Böttcher and Meisert 2011). During social interaction between individuals with variable learning styles, students engaging in deep learning approaches can provide cognitive stimulation to the other students in terms of cognitive tension between group members (Kyza et al. 2011). If cognitive tension develops into cognitive conflict, the group members eventually generate incompatible ideas. Cognitive conflict in group modeling can manifest in the criticism or evaluation of one's own models, or the models of others, and can be solved through justification and modification of the models based on evidence (Acher et al. 2007). In fact, social interaction in generating, evaluating, and justifying the models relates to the aims of argumentative discoursesense-making, articulating, and persuading - and this kind of discourse practice may enable students to engage in cognitive collaboration in a small group setting. Therefore, a group modeling task involving blood circulation was designed for our study to generate dynamic modeling practices through argumentative interaction. Cognitive collaboration and model development associated with statements reflecting deep learning approaches were also closely examined.

\section{Methods}

A case study method was chosen to explore the effect of statements associated with deep learning approaches (DLA) on collaborative group modeling. We selected one focal group (four students) among nine groups (34 students) who participated in small-group modeling lessons designed for our research. This focal group was appropriate for illustrating the complexities of the process in which group dynamics influenced cognitive collaboration and model development between students. The case study method adopted allowed us to understand the context of group modeling as well as students' backgrounds in-depth (Merriam 1988; Patton 1987). Also, using multiple sources of evidence, we intended to examine the collaborative modeling process of one focal group without bias, thereby improving the trustworthiness of the study (Yin 1989).

\section{Participants}

Thirty-four students in the eighth grade at K Girls' middle school in Incheon City, which is a metropolitan area in Korea, participated in small-group modeling lessons. They came from middle-class socioeconomic backgrounds. K Girls' middle school achieved a mid-upper level ranking in the national academic achievement assessment in 2011. We arranged the students in groups of three or four (nine groups), with the intent of ensuring heterogeneity of students' level of academic achievement within each group. First, we analyzed all models created by the nine groups to select one focal group for the case study. At this stage, four groups produced high-quality models that were similar to the target model. Among these four groups, we selected Group 6 to be our tentative focal group because all group 
members participated in group modeling process actively, and because of the large number of dialogic discourse patterns used by this group.

After selecting Group 6 as the tentative focal group, the changes in students' participation that emerged during the learning process were analyzed, based on data such as researchers' journals, a students' questionnaire, and report cards, in order to see whether Group 6 was suitable as a focal group (Table 1). Consequently, changes in participation patterns were identified in the students of Group 6; their responses in the post-questionnaire showed their increasing confidence in their own learning as the study proceeded. For instance, the leader of the group was not always the same person, but would change in the middle of the lesson. According to Bianchini (1997), the leader participates actively in cognitive interaction and makes the most contributions to the group learning. It is noteworthy that the leaders included both a high achiever and a low achiever: Students A and C both served as the leader. Another change was found in the students' confidence level: While low achievers showed less confidence about learning scientific concepts in the prequestionnaire, before the modeling-based lessons, all the group members became confident about understanding the concepts of blood circulation after taking the lessons, as was indicated in their responses to the post-survey questions concerning their understanding of the concepts. Moreover, students B and D, both of whom showed relatively low participation, demonstrated progress on their science tests (seen by comparing their pre- and post-test scores). Based on the above data, we assumed that there had been epistemic changes in science among the students in Group 6. We also assumed that these changes were caused by cognitive collaboration during group modeling, so their modeling processes were examined thoroughly.

Student labels were A, B, C, and D; this alphabetic order indicated a descending order of academic achievement

Table 1 Evidence for presuming epistemic changes in the focal group students

\begin{tabular}{lc}
\hline Data for evidence & Description of the evidence \\
\hline $\begin{array}{c}\text { Researchers' observations and } \\
\text { results of the lessons analysis }\end{array}$ & $\begin{array}{c}\text { The leader changed from high- } \\
\text { achieving learner A to low- } \\
\text { achieving learner C in the middle } \\
\text { of the lesson } \\
\text { All members participated in the } \\
\text { model elaboration process }\end{array}$ \\
$\begin{array}{c}\text { Post-questionnaire: questions } \\
\text { about confidence in learning } \\
\text { Changes in academic } \\
\text { achievements }\end{array}$ & $\begin{array}{c}\text { learning about circulation } \\
\text { Students B and D, who did not } \\
\text { actively participate in modeling, } \\
\text { made some progress }\end{array}$ \\
\hline
\end{tabular}

within the group. A description of the students in the focal group is shown in Table 2. The students were classified into the categories of deep learner and surface learner, based on the different science activities that stemmed from their approaches to learning science, as proposed by Chin and Brown (2000) (See Table 4). Using this framework, students $\mathrm{A}$ and $\mathrm{C}$ were revealed to be deep learners, while students B and D were surface learners. Students A and C made 23 and 21 statements, respectively, that demonstrated deep learning, about double the average frequency for this kind of statement. The learning approaches found in the analysis of the discourses showed consistency and were supported by the researchers' field notes, the student's worksheets, and the teacher's testimony.

The teacher who participated in this study had an eightyear history of teaching. She is currently working on a doctoral program in biology education at the graduate school. She had experience in studying small-group argumentation and was consistently committed to self-development by attending many kinds of training programs and meetings of science teachers. When one of the authors asked the teacher what kind of role she wanted to serve in her science lessons, she answered as follows:

I want to serve in the role of a helper who can make the context for students to investigate by themselves in science classroom.

When asked for her perceptions on group discussion and participation, she answered as follows:

I think that group discussion is the process that students learn by themselves and all group members contribute to the meaning making in group learning. Group discussion is more meaningful for individual students than lecture method instruction. For dynamic group discussion, I need to encourage the learning environment by providing appropriate learning materials, guiding individual students' roles, and encouraging setting of good group norms.

These interview data revealed that the teacher understood teaching and learning from a socioconstructive perspective. For example, she regarded herself as a helper who assisted students to explore by themselves and considered

Table 2 Description of the participants in the focal group

\begin{tabular}{lll}
\hline Students' ID & Learning approach & $\begin{array}{l}\text { Academic } \\
\text { achievement level }\end{array}$ \\
\hline A & Deep & High \\
B & Surface & Medium \\
C & Deep & Lower \\
D & Surface & Lower \\
\hline
\end{tabular}


how to make students participate actively in group modeling. This perception was reflected in her lessons as well. She provided clues to help students construct models by themselves instead of giving correct answers directly, and she encouraged the students to participate actively in modeling. She also helped the researchers revise the teaching and learning materials used in this study, and assisted in selecting the focal group by identifying the learning approaches of the students in that group, and inferring their epistemic changes from a subsequent science lesson.

\section{Task Characteristics of the Implemented lessons}

The researchers analyzed three modeling lessons about blood circulation, which were selected from the chapter "Digestion and Circulation" in the science text book used in the eighth grade. Students may find it difficult to understand the concept of blood circulation because it is invisible and hard to experience. It also involves a wide range of concepts, such as blood cells, oxygen, carbon dioxide, heart valves, heart, blood vessels, blood pressure, and so on (Buckley 2000). Each lesson consisted of $45 \mathrm{~min}$ in which the teacher guided the process of hands-on activities around the target phenomena for group modeling, and students practiced the hands-on activities and participated in small-groups and class discussions. The task for each lesson was a hands-on activity, which was developed so as to encourage students' cognitive participation in group modeling. In this way, we intended that the students would be able to understand the circulation of the blood, would maintain interest in the lessons, and eventually be able to construct the models collaboratively.

The characteristics of the lessons implemented are described in Table 3. The first lesson consisted of a siphon pump analogy modeling activity, which was designed to explain one-way water flow in the siphon pump. The analogy simplifies the target concept of the heart and gives a visual representation that supports students' understanding (Duit 1991). While the structures of the siphon pump and the heart are not same, the mechanisms of water flow and blood flow are similar. As students manipulated the siphon pump, they observed the one-way water flow due to the opening and closing of the valves, which was influenced by the contraction and relaxation of the pump. This simulation encouraged the students to reason spontaneously about single-direction water flow, to participate in cognitive chain-reaction through oral interaction, and to construct corresponding explanatory group models (see Table 9). In addition, the post-questionnaire analysis revealed that most students chose the siphon pump activity as being the most interesting and helpful activity for their conceptual understanding. Thus, this activity would help students sustain their interest in and better understanding the concept.

Students represented their models both orally and in writing in the first lesson. The model created in the first lesson was intended to explain the direction of water flow

Table 3 Characteristic of the implemented lessons

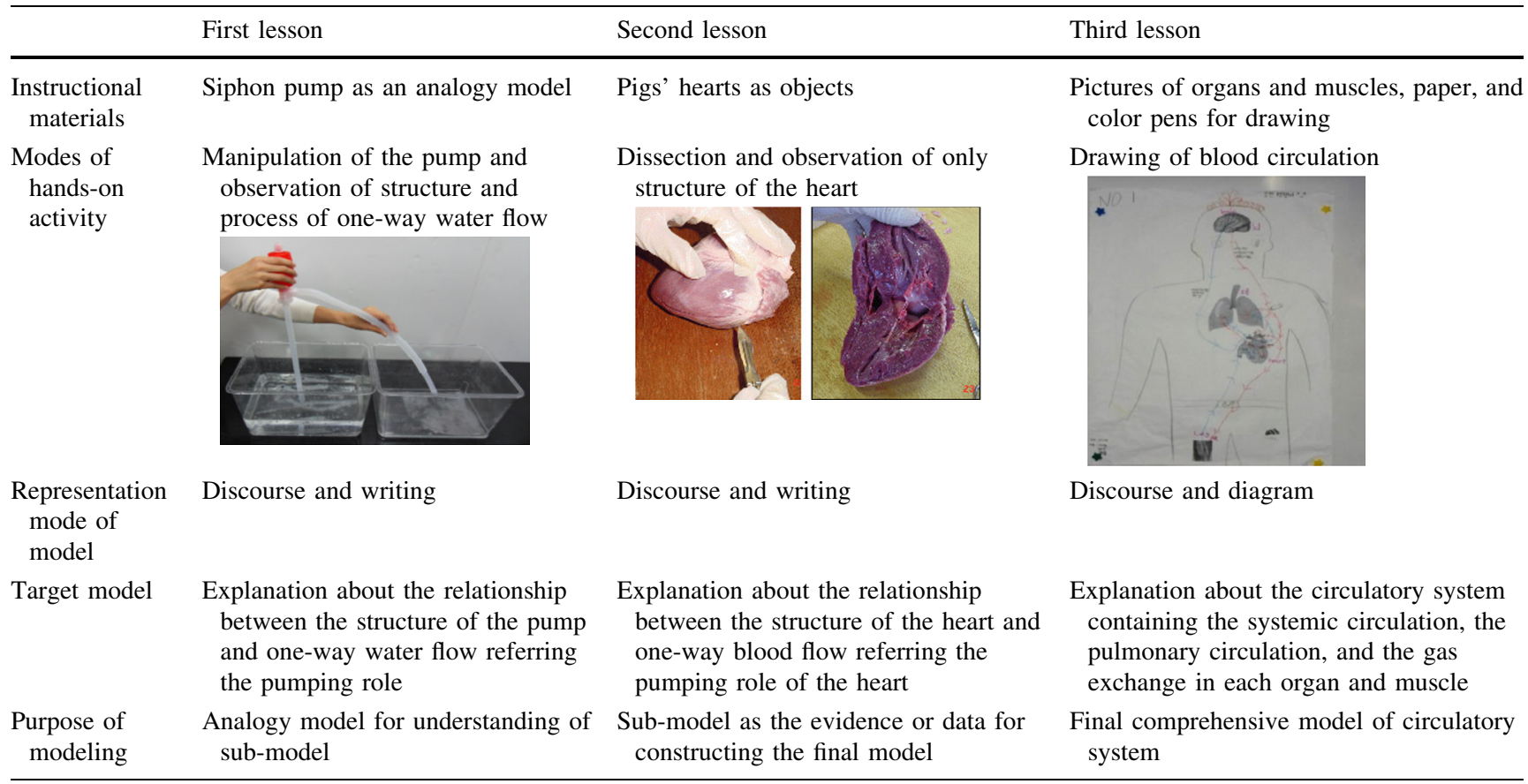


in the siphon pump, which is controlled by the opening and closing of the valves in the pipe, and which is affected by the contraction and relaxation of the pump. The students were expected to produce the following models: When the pump relaxes, the valve of the straight pipe opens and water comes up through the pipe. When the pump contracts, the valve of the straight pipe closes and water comes out of the pump through the opening of the valve in the curved pipe. Hence, the model created in the first lesson is used as an analogy for the subsequent model in the second lesson, enabling students to understand the mechanism of one-way blood flow through the heart.

The second lesson involved the dissection of pigs' hearts. In this lesson, students observed the components of the heart, such as the heart valves, atriums, ventricles, superior vena cava, pulmonary artery, and pulmonary veins. The analogy used in the first lesson involved a simple structure compared to the heart, so it focused only on certain aspects. Therefore, the students were now asked to observe a real pig's heart in order to recognize the differences between the object and the analogy (Grosslight et al. 1991). At this time, because they could not see the real blood circulation in the heart, the students constructed explanatory models of blood circulation through the heart by recalling the siphon pump modeling activity. In this lesson, two kinds of explanatory models were produced by each group: One model explained blood flow without the semilunar valve and tricuspid valve in the right chamber; the other one showed one-way blood flow in the heart with the heart pumping. Students' models were then represented both orally and in writing, as in the first lesson.

The models produced in the second lesson functioned as sub-models for understanding the models used in the third lesson. These provided various data to construct comprehensive models regarding blood circulation. Students were expected to learn the following concepts: Heart pumping is the power source of blood circulation; one-way blood flow is caused by the contraction and relaxation of the heart; oxygenated blood does not mix with deoxygenated blood because of the vessel wall which is in the middle of the heart; blood goes to each organ and muscle when it leaves the heart wall that is the thickest and therefore produces great pressure.

In the third lesson, each group drew a blood circulation diagram. Whereas 6-8 min was allotted for each group discussion in the previous lessons, $35 \mathrm{~min}$ was provided in the third lesson, occupying most of the lesson. The teacher served as a guide to introduce the modeling activities and then helped the students to draw blood circulation models by interacting with group members. Students recalled the models produced in previous lessons and constructed the models through group discussion by applying prior knowledge to the third lesson. The groups then drew a human figure on a large piece of paper and attached to it their pictures of the heart, brain, leg muscles, and lungs. They also drew the systematic circulation and pulmonary circulation. They then marked the oxygenated blood and deoxygenated blood using red and blue pens, respectively. Moreover, they wrote explanations about the gas exchange in the vessels and organs. Consequently, the students' explanatory models were represented both orally and in blood circulation diagrams. The models produced in this lesson were expected to contain three concepts: systemic circulation, pulmonary circulation, and the gas exchange in each organ and muscle.

\section{Data Collection and Analysis}

The three lessons on blood circulation were videotaped and audiotaped, and the discourse and gestures of the teacher and students were transcribed. The participants were asked to answer a pre-questionnaire before the lessons to check their perceptions of small-group activities and their roles in the group, as well as to investigate their prior knowledge regarding blood flow through the heart. After the lessons, a post-questionnaire was distributed to determine whether or not students' perceptions had changed. In addition, students' worksheets, the groups' blood circulation diagrams, and transcriptions were used to analyze the models and the modeling process. Models in the first and second lessons were analyzed with students' worksheets and transcriptions. Models in the third lesson were analyzed with the groups' blood circulation diagrams and transcriptions. A variety of supplementary materials, such as student reports, research journals, questionnaires, and interviews with the teacher, were also employed to gain in-depth understanding of the students' backgrounds and to grasp the context of the group modeling process.

The analysis of discourse was performed in four steps. In the first step, a total of eight episodes were identified, based on the sub-models of each lesson, with discourses recorded for each student across the whole episodes: Two episodes from the first lesson, two episodes from the second lesson, and four episodes from the third lesson. In other words, each episode involves a sub-model of the target model for each lesson. In the next step, the modeling phase of each episode was incorporated into model generation, elaboration, evaluation, and modification. In this step, we analyzed the students' specific statements that influenced the model development. Then, we identified the group dynamics as revealed in the group modeling process. We applied coding of the statements associated with DLA, as shown in Table 4, for the third step. We categorized the statements associated with DLA into five statement categories and then identified the statement type. The researchers conducted this process independently, reaching 
Table 4 Framework for the statements associated with deep learning approaches

\begin{tabular}{cll}
\hline $\begin{array}{l}\text { Statement } \\
\text { category }\end{array}$ & Statement type & Coding $^{\text {a }}$ \\
\hline $\begin{array}{c}\text { Generating } \\
\text { thinking }\end{array}$ & Present an idea & GT-a \\
$\begin{array}{c}\text { Nature of } \\
\text { explanation }\end{array}$ & Focus on explanation of the mechanism & GT-b \\
Asking & Nexplain with mini-theories or models & NE-b \\
questions & Request information about mechanism & AQ-a \\
Metacognitive & Resolve discrepancies in knowledge & AQ-b \\
activity & Evaluate own idea & MA-a \\
& Evaluate other's ideas & MA-b \\
& Evaluate task process & MA-c \\
& Reflect on standards & MA-d \\
& Reflect on positive understanding & MA-e \\
& Reflect on lack of understanding & MA-f \\
Approach to & Regulate action & MA-g \\
task & Persist in following up on an idea with & AT \\
& some sustained interest before moving & \\
& to another one &
\end{tabular}

a OO-alphabetic order indicates statement category-statement-type order. $G T$ generating thinking, $N E$ nature of explanation, $A Q$ asking questions, $M A$ metacognitive activity, $A T$ approach to task

an agreement in further discussion about some issues that emerged. Lastly, the relationship between the statements associated with DLA and model development was identified by analyzing the group dynamics, which was based on the previous three steps.

The statements associated with a deep learning approach were classified into one of five categories using the framework developed by Chin and Brown (2000) (see Table 3), in which the characteristics of deep learners in learning science are shown. According to Chin and Brown (2000), deep learners spontaneously present ideas and venture ideas for sustainable thinking in terms of generating thinking. With regard to the nature of explanation, they tend to focus on explaining mechanisms and obscure phenomena using mini-theories or models. They also request information about the mechanism and ask open and reflective questions that focus on resolving discrepancies in their knowledge. In terms of their metacognitive activity, using reflective thinking, they evaluate not only their own and others' ideas but also task process, standard, and understanding. They also regulate actions by themselves. Finally, with regard to approach to task, they persist in following up on an idea with sustained interest before moving on to another one. Approach to task was not counted in this study, as the characteristics associated with approach to task are hard to identify from one single statement.
Table 5 Group 6's discourse analysis on Episode 1 from lesson 1

\begin{tabular}{|c|c|c|c|}
\hline & Speaker & Statement & Coding \\
\hline 1 & Teacher & $\begin{array}{l}\text { Observe the surface of both pumps A } \\
\text { (normal pump) and B (valve-less pump), } \\
\text { open the top, and take a look at inside } \\
\text { structure. Then try to explain how these } \\
\text { two pumps lead to different results } \\
\text { regarding water flow }\end{array}$ & \\
\hline 2 & B & Which one has the valve? & \\
\hline 3 & A \& C & (Pointing at the normal pump) This one & \\
\hline 4 & A & $\begin{array}{l}\text { How does the valve make one-way water } \\
\text { flow? Isn't it awesome? }\end{array}$ & AQ-a \\
\hline 5 & B & You know, water gets through the cover & \\
\hline 6 & $\mathrm{D}$ & (stops saying when B starts saying) & \\
\hline 7 & $\mathrm{C}$ & Water is not flowing backwards... & \\
\hline 8 & A & $\begin{array}{l}\text { (Pointing at valve-less pump) Does water } \\
\text { flows like this? }\end{array}$ & GT-b \\
\hline 9 & $\mathrm{C}$ & $\begin{array}{l}\text { Water just flows up and down in it (valve- } \\
\text { less pump) }\end{array}$ & \\
\hline 10 & $\mathrm{~B}$ & Because the valve blocks & \\
\hline 11 & $\mathrm{C}$ & $\begin{array}{l}\text { Water flows up and then flows in this way } \\
\text { since it's blocking here }\end{array}$ & NE-a \\
\hline 12 & A & $\begin{array}{l}\text { No, I'm asking whether water goes up from } \\
\text { here. (indicating from the bottom to the } \\
\text { top of the pipe) }\end{array}$ & AQ-a \\
\hline 13 & $\mathrm{C}$ & $\begin{array}{l}\text { It (valve) opens when water flows up like } \\
\text { this }\end{array}$ & \\
\hline 14 & A & (Observing pumping at the same time) & \\
\hline 15 & C & Look, it's flowing up & \\
\hline
\end{tabular}

$\overline{A Q-a \text { request information about mechanism, } G T-b \text { venture an idea, }}$ $N E-a$ focus on explanation of the mechanism

We employed the classification criteria of Chin and Brown (2000) and elaborated the framework with the consensus of the co-authors to encode the students' statements associated with DLA. Denzin and Lincoln (2005) stressed that it is important that researchers agree on improving the validity of qualitative research. Following their opinions, a doctoral student majoring in science education (together with the authors) independently analyzed the students' performances during modeling practices (Table 3) and a consensus was eventually reached on some areas of disagreement.

Table 5 shows a well-presented episode in which we identified the statements associated with DLA produced by students A and C. This episode was extracted from Group 6's modeling in lesson 1 . The teacher asked the students to observe two kinds of siphon pump structures and then to discuss differences between them in terms of water flow and structure. In Line 2, student B asked, "Which one has a valve?" and simply checks the difference in structure between pumps A and B. This statement contributed to the modeling process as a type of cognitive participation. However, it did not code as statements associated with 
DLA because it did not ask about the mechanism of oneway water flow, or about the discrepancies in the student's understanding. As opposed to this question, student A asked a question about the principle of one-way water flow (Line 4). Later, she raised another question about the pump structure and the principle of water flow, thereby adding to student C's explanation (Line 11) and continuing the discussion (Line 12). This was coded as request information about mechanism (AQ-a). Her efforts triggered the reasoning for model elaboration regarding one-way water flow in the pump. The statement in Line 8 was also a question, but was coded as venture an idea (GT-b). That was because it did not ask about the mechanism of the target phenomena, but criticized the error in student C's utterance (Line 7).

Meanwhile, when student B responded to A's questions with "Water gets through the cover" and "Because the valve blocks" (Lines 5 and 10), these were not explanations that related logically to the cause of events. Student C also gave simple answers that were just descriptions of the phenomena (Lines 7 and 9). These statements were not coded as statements associated with DLA because they focused on a description of an observation. Student C, however, tried to give a logical explanation by linking water flow and valve movement (Line 11), which could be viewed as focus on explanation of the mechanism (NE-a). Her statement associated with DLA contributed to model development because it ensured that reasoning between group members kept taking place.

\section{Results}

The objective of this study was to explore the cognitive collaboration and corresponding model development affected by deep learning approaches during group modeling of blood circulation. We conducted a case study with Group 6, in which cognitive collaboration was expected to be actively taking place within group members' epistemic changes. The cognitive collaboration and modeling process influenced by students' statements associated with deep learning approaches (DLA) in Group 6 were analyzed thoroughly. In this section, the presented episodes represent the notion that group dynamics and cognitive collaborations proceeded according to the model's developmental phases.

The analysis of the discourses showed that the specific statements associated with DLA that was used contained some of the aims of argumentative discourse practice: sense-making, articulating, and persuading. These kinds of statements associated with DLA enabled the modeling process to proceed through model generation, elaboration, evaluation, and modification. They also helped to enhance the understanding and participation of group members. Based on the specific function of statements associated with DLA, cognitive collaboration was categorized into cognitive scaffolding and critical monitoring.

\section{Cognitive Scaffolding}

Vygotsky (1978) suggested the notion of the zone of proximal development (ZPD), which is the distance between the actual and the potential developmental level. A student can reach the potential developmental level with the help of the scaffolding provided by an adult guide or by peers who are more capable. The provision of scaffolding can enhance the understanding of students who have not yet reached their potential developmental level and can help them to identify concepts (Hogan and Pressley 1997). In cognitive collaboration, scaffolding ensures a highquality learning process in which the group members have different levels of cognitive ability (Wood et al. 1976). In this study, the deep learners in Group 6 prompted other group members to participate in the modeling process by producing the nature of explanation (NE) and asking questions (AQ), which involved the aims of the argumentative discourse, such as sense-making. These statements served as cognitive scaffolding, influencing the group dynamics and the modeling process, such as the model generation and elaboration phases.

\section{Model Generation Phase}

- The statements associated with DLA served as cognitive scaffolding with the aims of sense-making and articulating, which led to the model generation phase.

During the model generation phase, students are required to have creative and evaluative thinking skills. This is because model generation is not about a simple description of a phenomenon; instead, it is similar to the process of creating a new concept using various representation skills (Wells et al. 1995). In this phase, students collect data that can be used as evidence in order to produce the best model to describe the phenomenon (Louca et al. 2011). The knowledge to be used as evidence may be obtained through experiments, from a literature review, or it might already exist as prior knowledge (Justi and Gilbert 2002). After gathering evidence for the construction of a model, students need particular thinking skills to select appropriate model components. In other words, even though the students experience the same process for the collection of data, they use different amounts and kinds of data according to their knowledge bases, learning strategies, and thinking skills. Hence, deep learning approaches will be a 
critical element in thinking in-depth about the components of the model, with the goal of making sense of the target phenomenon.

With regard to the modeling process developed by Group 6, the first model was generated when a student who demonstrated a deep learning approach articulated statements involving sense-making around the principles of blood circulation. In five out of eight episodes, student A, a high-achieving student with a deep learning approach, was the first to demonstrate model generation. However, there were three episodes in which other students initiated the generation of the model; therefore, we need to analyze these episodes in order to examine the roles of the members and the cognitive collaboration that occurred. Student A generally initiated model generation and served as a role model for the other students. Student C, who had a deep learning approach but lacked a well-developed knowledge base, contributed to the generation of two models. This might be interpreted as the model generation skills shown by student A having provided cognitive scaffolding for student $\mathrm{C}$. In addition, the model development was accompanied by students' cognitive participation, triggered by their statements associated with DLA. This process is identified in Tables 6, 7, and 8. Three episodes were selected from the third lesson: One was about the hearthand muscle circuit, another was about the heart-brain circuit, and the third was about pulmonary circulation.

- Students responded to statements associated with DLA differently according to their learning approaches.

In Table 6, the statement types of the statements associated with DLA were provided in the coding column if the students' statements were associated with DLA. In the model developed column, the corresponding modeling phase and the constructed group model were described. As in the other groups, students in Group 6 had difficulty in starting to draw the diagram at the beginning of the lesson (Table 6). At that time, student A, who had a deep learning approach, stated, "Let's draw it just like spreading through the whole body," (Line 2). This can be interpreted as the statements associated with DLA focus on explanation of the mechanism (NE-a) since her statement pointed out that the heart's pumping is the driving force of blood circulation. Her suggestion showed that she applied the data obtained from previous lessons to the new modeling activity and that she initiated the model generation regarding the heart-hand muscle circuit. An important feature must be noted here: Although all the students in Group 6 had obtained their data for the model generation from the same learning experiences, their performance in applying the data to the new model generation varied, depending on their learning approaches.

Student A's statements associated with DLA (Line 2) established a foundation for the group model development and influenced the other students' cognitions. However, her statement associated with DLA impacted the others in varying ways. For instance, student D accepted A's statements associated with DLA regarding blood circulation literally, as the heart being the driving force. Student D, a surface learner, could only present blood spreading to the whole body, from the heart, across the whole paper (Line 3) but failed to note that the blood flow started from the aorta by reasoning out the relationship between the heart's pumping and the heart's structure. Contrastingly, student C, who has a deep learning approach, accepted student A's statement in a different way. She integrated student A's idea into her own conception that the blood from the heart flows to the particular branch of the body through the aorta. Consequently, student $\mathrm{C}$ demonstrated the statement associated with DLA present an idea (GT-a), which combined her own idea with A's. Her attempt led to a group model elaboration by adding a model constituent to the existing model. This can be viewed as sense-making, which is one of the aims of argumentative discourse (Line 5).

During the process of model generation for the heartbrain circuit, student A again emphasized the pumping role of the heart (Table 7). She raised questions about the concept that "blood circulation initiates in the brain" presented in the group model, which contradicted her perception that "blood circulation initiates in the heart," which was expressed in the previous lesson (Line 1). This
Table 6 Episode 1 in lesson 3 (Systemic circulation: hearthand muscle circuit)

$N E$ - $a$ focus on explanation of the mechanism, $G T$ - $a$ present an idea

\begin{tabular}{|c|c|c|c|c|}
\hline & Speaker & Statement & Coding & Model development \\
\hline 1 & $\mathrm{D}$ & How should we draw? & & \\
\hline 2 & A & $\begin{array}{l}\text { Let's draw it just like } \\
\text { spreading through the whole } \\
\text { body }\end{array}$ & NE-a & $\begin{array}{l}\text { Model generation: [The heart's pumping is the } \\
\text { driving force of blood circulation] }\end{array}$ \\
\hline 3 & $\mathrm{D}$ & $\begin{array}{l}\text { Here and here (pointing with a } \\
\text { pen) }\end{array}$ & & \\
\hline 4 & A & Draw a line from here to here & & \\
\hline 5 & $\mathrm{C}$ & $\begin{array}{l}\text { I will draw the artery...comes } \\
\text { out of the aorta }\end{array}$ & GT-a & $\begin{array}{l}\text { Model elaboration: [Pathway of the heart-hand } \\
\text { circuit: heart } \rightarrow \text { aorta } \rightarrow \text { (hand muscle)] }\end{array}$ \\
\hline
\end{tabular}


Table 7 Episode 2 in lesson 3 (Systemic circulation: heart-brain circuit)

\begin{tabular}{|c|c|c|c|c|}
\hline & Speaker & Statement & Coding & Model development \\
\hline 1 & A & $\begin{array}{l}\text { It's not the brain. } \\
\text { Blood doesn't } \\
\text { spread from the } \\
\text { brain. Where does } \\
\text { blood come from? } \\
\text { Now? }\end{array}$ & \multirow[t]{5}{*}{ AQ-b } & \multirow[t]{5}{*}{$\begin{array}{l}\text { Model generation: } \\
\text { [Heart-brain blood } \\
\text { circulation initiates } \\
\text { in the heart] }\end{array}$} \\
\hline 2 & $\mathrm{C}$ & $\begin{array}{l}\text { This is the aorta; } \\
\text { that's the superior } \\
\text { vena cava }\end{array}$ & & \\
\hline 3 & $\mathrm{D}$ & $\begin{array}{l}\text { It's (the brain) } \\
\text { unique here }\end{array}$ & & \\
\hline 4 & $\mathrm{C}$ & $\begin{array}{l}\text { Hey, isn't it thin } \\
\text { here? }\end{array}$ & & \\
\hline 5 & $\mathrm{D}$ & $\begin{array}{l}\text { Let's draw a line } \\
\text { thicker on that } \\
\text { place }\end{array}$ & & \\
\hline 6 & $\mathrm{C}$ & $\begin{array}{l}\text { There are only two } \\
\text { vessels connecting } \\
\text { here }\end{array}$ & MA-c & $\begin{array}{l}\text { Model evaluation at } \\
\text { superficial } \\
\text { component level }\end{array}$ \\
\hline & & & & $\begin{array}{l}\text { [Pointing out the } \\
\text { issue with drawing } \\
\text { only two capillary } \\
\text { vessels in the } \\
\text { brain] }\end{array}$ \\
\hline
\end{tabular}

$\overline{A Q-b \text { resolve discrepancies in knowledge, } M A-c \text { evaluate task process }}$

statement associated with DLA involved resolving discrepancies in knowledge (AQ-b) and triggered the generation of the heart-brain model. As with the episode described in Table 6, this statement associated with DLA provided a cognitive foundation for the other group members and enabled them to develop the heart-brain circuit model and to initiate another model. However, the students showed different reactions toward the same statement associated with DLA due to the differences in their own learning approaches.

Student D, with a surface learning approach, did not monitor student A's statement associated with DLA but just rationalized the existing model by stating that the brain in their group model is uniquely different from the other ordinary brain (Line 3). Moreover, she did not modify the incorrect idea that "blood flow starts from the brain," and she fabricated the drawing as if the cerebral vein was the aorta. In drawing the vessel that started from the brain, she attempted to make it thicker without any idea about the principles of blood circulation (Line 5). Contrastingly, student $\mathrm{C}$, who has a deep learning approach, performed differently in response to student A's statement associated with DLA, trying to interpret A's statement associated with DLA against her own knowledge (Lines 2 and 4). This student understood the problem suggested by student A (Line 1) and discovered another problem in their group model, pointing out that there were only two capillaries in the brain (Line 6), which implied that she perceived the brain not as the driving force behind blood circulation but as one of the organs that receive oxygenated blood from the heart. As student $\mathrm{C}$ recognized and articulated the error in the group model, her statement was coded as evaluate task process (MA-c). This statement associated with DLA had the function of evaluating the model and causing the group model to be modified.

- Student A's statements associated with DLA contained the model of the branched systemic circulation and served as cognitive scaffolding.

Two kinds of misconception were found in other groups. One was the linear circuit concept: "In the systemic circulation, the blood flows from the heart, goes through each organ and muscle in turn, and then flows back to the heart." The other was the wrong driving power concept: "The oxygenated blood flows from the lungs to each organ and muscle." As a matter of fact, these misconceptions are similar to those held by students related to blood circulation found by Chi et al. (1994). Buckley (2000) gave an explanation about the major misconceptions regarding blood circulation that were similar to those of Chi's (2005) ontological category explanation. Buckley (2000) reported the misconception that blood circulation was the emergent process since the flow of blood to each organ occurs randomly due to the force of the heartbeat and the blood circulation, and the circulation is completed through continuous interaction between the constituents of the circulatory system such as the heart, vessels, and blood. In this study, some students, with the exception of Group 6, constructed group models that were quite different from the target model of this study.

However, it should be noted that the model constructed by Group 6, represented in the diagram, did not exhibit these errors. This is because students in Group 6 had a clear perception of the pumping role of the heart, which had been articulated by student A's statement associated with DLA, as shown in the episodes reported in Tables 6 and 7. Accordingly, they realized that the heart-hand muscle circuit did not connect with the heart-brain circuit, and they understood that the lungs did not pump. In other words, due to student A's statement associated with DLA, the students in Group 6 learned the sub-model of blood circulation and the systemic circuit as the emergent process. Therefore, their model had a branched systemic circulation pathway, and they showed the correct flow of oxygenated blood to each organ.

Student A's statement associated with DLA not only initiated the model generation but also provided a scaffolding for the other students to participate in the modeling 
process that followed. During this process, however, students reacted differently, depending on their learning approaches. While student $\mathrm{D}$, with a surface learning approach, accepted student A's opinion literally, student C, with a deep learning approach, monitored student A's statement associated with DLA and connected it to her own ideas.

- Cognitive scaffolding affected the cognitive participation of group members.

Moreover, student A's statement associated with DLA helped student $\mathrm{C}$ to initiate the modeling of the pulmonary circulation. As student $\mathrm{C}$ showed cognitive participation during the process of model generation and elaboration by applying the key principle that "the heart's pumping is the driving force of blood circulation," presented by student A, this also provided cognitive scaffolding. Episode 4 in Table 8 shows how student $\mathrm{C}$ contributed to the pulmonary model generation and elaboration phases. Student $C$ initiated pulmonary model generation by suggesting the statements associated with DLA focus on explanation of the

Table 8 Episode 4 in lesson 3 (Pulmonary circulation)

\begin{tabular}{|c|c|c|c|c|}
\hline & Speaker & Statement & Coding & Model development \\
\hline 1 & $\mathrm{C}$ & $\begin{array}{l}\text { The pulmonary } \\
\text { arteries are blue in } \\
\text { color because } \\
\text { blood in the } \\
\text { pulmonary arteries } \\
\text { goes out from the } \\
\text { heart } \\
\text { Blood flows through } \\
\text { pulmonary arteries, } \\
\text { pulmonary } \\
\text { capillaries, } \\
\text { pulmonary veins, } \\
\text { left atrium, and left } \\
\text { ventricle }\end{array}$ & NE-a & $\begin{array}{l}\text { Model generation: } \\
\text { [Pulmonary } \\
\text { circulation initiates } \\
\text { in the heart] } \\
\text { Model elaboration: } \\
\text { [Pathway of the } \\
\text { pulmonary } \\
\text { circulation: } \\
\text { Heart } \rightarrow \text { the } \\
\text { pulmonary } \\
\text { artery } \rightarrow \text { the } \\
\text { pulmonary } \\
\text { capillary } \rightarrow \text { the } \\
\text { pulmonary } \\
\text { vein } \rightarrow \text { heart] }\end{array}$ \\
\hline 2 & D & $\begin{array}{l}\text { Where was the blood } \\
\text { purified? }\end{array}$ & AQ-a & $\begin{array}{l}\text { Stimulation of model } \\
\text { elaboration }\end{array}$ \\
\hline 3 & $\mathrm{C}$ & $\begin{array}{l}\text { (pointing outward) } \\
\text { From here }\end{array}$ & & $\begin{array}{l}\text { Model elaboration: } \\
\text { [Place of gas } \\
\text { exchange (lungs)] }\end{array}$ \\
\hline 4 & D & $\begin{array}{l}\text { And then it flows } \\
\text { into here }\end{array}$ & & \\
\hline 5 & $\mathrm{C}$ & $\begin{array}{l}\text { These are the } \\
\text { pulmonary veins } \\
\text { because the veins } \\
\text { go into the heart. } \\
\text { We should draw } \\
\text { the veins, the left } \\
\text { atrium, the left } \\
\text { atrium, and the left } \\
\text { ventricle }\end{array}$ & NE-a & $\begin{array}{l}\text { Model elaboration: } \\
\text { [Marking the } \\
\text { oxygenated blood } \\
\text { in the pulmonary } \\
\text { vein, the left } \\
\text { atrium, and the left } \\
\text { ventricle] }\end{array}$ \\
\hline
\end{tabular}

$\overline{A Q-a \text { request information about mechanism, } N E-a \text { focus on expla- }}$ nation of the mechanism mechanism (NE-a), which acted as a stimulant to others' cognitions and encouraged others to participate actively in the modeling process (Line 1). She emphasized that the heart was the driving force of pulmonary circulation, stating, "blood in the pulmonary arteries goes out from the heart." Student C applied the mechanism that was produced by student A during the initial systemic circulation modeling, using it to continue initiate the pulmonary circulation modeling. This implied that student $\mathrm{C}$ had internalized student A's statement associated with DLA regarding the mechanism of the driving force of blood circulation. Furthermore, student $\mathrm{C}$ subsequently mentioned all the pathways of pulmonary circulation, and the model was then elaborated on in a series of cognitive participations by the other students.

In addition, it was noted that student $\mathrm{D}$ showed cognitive participation in the discussion on pulmonary circulation by stating the statement associated with DLA. Even though she did not initiate the modeling, she critically accepted student C's statement. Student C's argumentative participation in the previous modeling might have served a role as scaffolding for student $\mathrm{D}$. Student $\mathrm{D}$ pointed out the mechanism of gas exchange in the lungs, which had been missing from student C's statement associated with DLA. This kind of statement associated with DLA was an example of request information about mechanism (AQ-a), while the purpose of the argumentative discourse, sensemaking, was well presented (Line 2). Student $\mathrm{C}$ articulated the gas exchange by pointing to the lung on the blood circulation diagram in response to student D's question (Line 3). Thereafter, student $\mathrm{D}$ also pointed out the next pathway of pulmonary circulation (Line 4). Although this statement was not associated with DLA, it was a voluntary participation in the model development process during the model elaboration phase. In addition to student D's statement, student $\mathrm{C}$ explained the reason why the place that student $\mathrm{C}$ had pointed to was the pulmonary vein (Line 5), so this was the statement associated with DLA focus on explanation of the mechanism (NE-a). Her statement was the summation of the group discussion, and, at the same time, it helped the students with their model elaboration (Line 5).

\section{Model Elaboration Phase}

- The questions associated with DLA served as cognitive scaffolding with the aims of sense-making, which led to the model elaboration phase.

In the science classroom, the questions generated by students lead to productive discussions and the meaningful construction of knowledge (Chin and Chia 2004). There are two kinds of deep approach questions in the statement 
associated with DLA: request information about mechanism (AQ-a) and resolve discrepancies in knowledge (AQb). Both of these questions involve the argumentative discourse aim of sense-making (Berland and Reiser 2011) because they originate from inquiries about the mechanism, and look for conflicts within the acquired knowledge, thereby intending to solve the problem. Students' deep approach questions enable them to connect a new concept to their current understanding and to participate in group interaction during the process of resolving cognitive discrepancies (Chin and Chia 2004). In the case of Group 6, the focus on explanation of the mechanism (NE-a) triggered another statement associated with DLA, playing the role of cognitive scaffolding to the other students. Thus, all students in Group 6 were able to participate in the reasoning process, and most eventually made contributions to the elaboration of the group model.

Episode 2 in the first lesson demonstrated this process (Table 9). The students attempted to construct an explanatory model regarding the one-way water flow mechanism by applying the inner structure of the siphon pump. Student A proposed the initial model, stating, "Water flows upwards in the straight pipe when the pump contracts," and she asked a question involving request information about mechanism (AQ-a), which stimulated the elaboration of the model (Line 1). Some chains of reasoning emerged because of this statement associated with DLA; that is, many students participated in the model elaboration process by referring to some statements associated with DLA. It is worth noting that students B and D, both surface learners, presented their own statements associated with DLA and showed cognitive participation during the process of group modeling.

Student B answered student A's question about the mechanism and presented an explanatory idea by linking it to the pump structure as present an idea (GT-a), which elaborated on the model by adding the idea that the valve in the straight pipe influenced the water flow (Line 2). However, student B could not give a clear explanation about water flow in the pump; therefore, student $\mathrm{A}$ then presented a specific model showing that water flow was affected by the movement of the valve, and she expressed the statement associated with DLA focus on explanation of the mechanism (NE-a) when she tried to give an explanation about the mechanism related to the original questions (Line 3). At the same time, she asked an in-depth question seeking to resolve discrepancies in knowledge (AQ-b) when she noticed the gap between student B's explanation (Line 2) and her own expected explanation (Line 4). This kind of question stimulated the model elaboration by
Table 9 Episode 2 in lesson 1 (One-way water flow in the siphon pump)

\begin{tabular}{|c|c|c|c|c|}
\hline & Speaker & Statement & Coding & Model development \\
\hline 1 & A & $\begin{array}{l}\text { (Operating the } \\
\text { pump) water flows } \\
\text { upward by pushing } \\
\text { it (pump) and } \\
\text { putting it } \\
\text { back...no... How } \\
\text { does it work? }\end{array}$ & AQ-a & $\begin{array}{l}\text { Stimulation of } \\
\text { model elaboration: } \\
\text { [Water flows up } \\
\text { through the } \\
\text { straight pipe when } \\
\text { the pump } \\
\text { contracts] }\end{array}$ \\
\hline 2 & B & $\begin{array}{l}\text { This is because the } \\
\text { valves hit and push } \\
\text { up the water. } \\
\text { Right? }\end{array}$ & GT-a & $\begin{array}{l}\text { Model elaboration: } \\
\text { [When the pump } \\
\text { contracts, the valve } \\
\text { in straight pipe } \\
\text { drives the water } \\
\text { upward] }\end{array}$ \\
\hline 3 & A & $\begin{array}{l}\text { No, it (the valve of } \\
\text { the straight pipe) } \\
\text { closes when you } \\
\text { push it, but it } \\
\text { opens when it } \\
\text { turns back }\end{array}$ & NE-a & $\begin{array}{l}\text { Model elaboration: } \\
\text { [Once the pump } \\
\text { contracts, the valve } \\
\text { in the straight pipe } \\
\text { closes and vice } \\
\text { versa }\end{array}$ \\
\hline 4 & & $\begin{array}{l}\text { Why does it work } \\
\text { like this? }\end{array}$ & AQ-b & $\begin{array}{l}\text { Stimulation of } \\
\text { model elaboration }\end{array}$ \\
\hline 5 & $\mathrm{C}$ & $\begin{array}{l}\text { I think that water in } \\
\text { here flows to here } \\
\text { (curved pipe) } \\
\text { when you push it } \\
\text { (pump head). If } \\
\text { you put away your } \\
\text { hand, water flows } \\
\text { upward and saves } \\
\text { in here (pump } \\
\text { head) }\end{array}$ & NE-a & $\begin{array}{l}\text { Model elaboration: } \\
\text { [Water flows up } \\
\text { through the curved } \\
\text { pipe when the } \\
\text { pump contracts. } \\
\text { Once the pump } \\
\text { relaxes, water } \\
\text { flows upward and } \\
\text { is saved in the } \\
\text { pump head.] }\end{array}$ \\
\hline 6 & A & $\begin{array}{l}\text { Can water be saved } \\
\text { in the pump head? }\end{array}$ & & \\
\hline 7 & $\mathrm{C}$ & $\begin{array}{l}\text { Here (pump head) is } \\
\text { the water }\end{array}$ & GT-a & \multirow{4}{*}{$\begin{array}{l}\text { Model elaboration: } \\
\text { [When the pump } \\
\text { contracts, water in } \\
\text { the pump head } \\
\text { flows toward the } \\
\text { curved pipe.] }\end{array}$} \\
\hline 8 & B & $\begin{array}{l}\text { So the saving water } \\
\text { flows down like } \\
\text { this }\end{array}$ & GT-a & \\
\hline 9 & $\mathrm{D}$ & $\begin{array}{l}\text { That's why water } \\
\text { drops from the } \\
\text { cover }\end{array}$ & GT-a & \\
\hline 10 & A & $\begin{array}{l}\text { Isn't it because it } \\
\text { (the valve in the } \\
\text { curved pipe) closes } \\
\text { and blocks water } \\
\text { going downward? }\end{array}$ & NE-a & \\
\hline 11 & $\mathrm{C}$ & $\begin{array}{l}\text { So saving water in } \\
\text { here drains out } \\
\text { when pushing the } \\
\text { pump. That's why } \\
\text { there is no water } \\
\text { inside. Once it } \\
\text { sucks again, water } \\
\text { turns up again }\end{array}$ & NE-a & $\begin{array}{l}\text { Model } \\
\text { reinforcement }\end{array}$ \\
\hline
\end{tabular}


Table 9 continued

\begin{tabular}{|c|c|c|c|c|}
\hline & Speaker & Statement & Coding & Model development \\
\hline 12 & A & $\begin{array}{l}\text { So (water) can't } \\
\text { drain out when the } \\
\text { valve (in the } \\
\text { straight pipe) } \\
\text { closes }\end{array}$ & & \\
\hline 13 & $\mathrm{C}$ & Yes & & \\
\hline 14 & A & $\begin{array}{l}\text { I see. Pushing it } \\
\text { drives water out }\end{array}$ & & \\
\hline 15 & $\mathrm{D}$ & $\begin{array}{l}\text { That's how water is } \\
\text { saved in the pump }\end{array}$ & & \\
\hline
\end{tabular}

$A Q-a$ request information about mechanism, $A Q-b$ resolve discrepancies in knowledge, $G T$ - $a$ present an idea, $N E-a$ focus on explanation of the mechanism

drawing answers to explain the mechanisms of water flow and valve movement. To answer student A's question, student $\mathrm{C}$ presented an idea that added to student B's explanation (Line 2): She expressed that "water flows in a single direction with the contraction and relaxation of the pump as water can be saved in the pump head" (Line 5).

The question that was asked about the mechanism (Line 1) focused on a key model constituent regarding the oneway water flow in the pump. Moreover, another in-depth question (Line 4) required additional explanations about the group model in order to resolve knowledge gaps between themselves and others. In this way, these statements associated with DLA provided cognitive scaffolding for the elaboration of the model by asking others' opinions. As the questions enlightened the students about the need to elaborate on the group models, these statements associated with DLA were regarded as metacognitive scaffolding. Kim and Hannafin (2011) defined metacognitive scaffolding as providing help related to planning, evaluating, and reflecting in order to regulate the learning process. The group model was elaborated on and developed as a result of metacognitive scaffolding. For example, students' perceptions developed from "water flows up through the straight pipe when the pump contracts" (Line 1) to "Water flows up through the straight pipe when the pump contracts. Once the pump relaxes, water flows upwards and can be saved in the pump head by closing the valve in the straight pipe."

- Students shared their understanding of the elaborated group model through statements associated with DLA.

In addition, the discourse of students in Group 6 revealed that they shared an elaborated group model. Student A asked for new information about whether or not the pump head could save the water, confirming the information that had originated in the process of obtaining answers to the first question (Line 6). Almost at the same time, students B, C, and D expressed present an idea (GT-a) by answering, "When the pump contracts, water in the pump head flows toward the curved pipe" (Lines 7, 8, and 9). This showed that, with the exception of student A, everyone understood the idea that "the saved water flows out from the pump head when the pump contracts." They contributed to the development of the group model because they added the content, "The valve movements enable oneway water flow, since water can be saved because of the valve movement." Moreover, student $\mathrm{C}$ reinforced the explanatory model (Line 11), and the question raised by student $\mathrm{A}$ in the first place was completely resolved. The group model was completed because of the cognitive interactions within the group, and we could identify that the students in Group 6 were able to understand the mechanism of the target model.

A modeling activity by scientists is intended to construct explanations about a scientific phenomenon, and this can be the key to science learning (Harrison and Treagust 2000). This is because students practice evidence-based explanatory activities involving the integration of constructed knowledge and understanding through scientific inquiry in class (Windschitl et al. 2008). The students' indepth questions tend to ask "how" or "why" instead of "what." Hence, an elaboration of the model was stimulated by requiring sense-making of the phenomenon. Answers to this type of question cannot simply describe the phenomenon; they also need to explain the mechanisms, thereby providing students with cognitive scaffolding. This is why a modeling process involving scientific explanations was conducted. In addition to scaffolding, cognitive participation was also found in students B and D, who were categorized as surface learners. Although they could not answer student A's question in the beginning (Lines 1 and 4), they were later able to understand the mechanism of a one-way water flow in the pump because student C's statement associated with DLA focus on the mechanism (Line 5) functioned as cognitive scaffolding. The findings showed that student B, C, and D participated in the model elaboration process by adding additional explanations of the mechanism (Lines 7, 8, and 9).

\section{Critical Monitoring}

\section{Model Evaluation and Modification Phases}

- The statements associated with DLA served as a form of critical monitoring that had the intent of persuading, sense-making, and articulating, which led to the model evaluation and modification phases.

Critical monitoring involves checking one's own or others' understanding, and it is a critical characteristic of the scientific activity used by deep learners (Chin and Brown 
2000). It can play an important role when students are engaged in an activity that requires them to work collaboratively to explain a phenomenon (Oliveira and Sadler 2008). Students' knowledge bases vary; therefore, their justification for their different assertions, and their agreement or disagreement regarding these opinions, emerge (Böttcher and Meisert 2011). Monitoring is important in this process required by the sense-making of the explanations discussed on a social plane. Monitoring has the persuading goal of argumentative discourse and can trigger criticism and evaluation (Berland and Reiser 2011). During this process, the quality of the models and the reasoning can be enhanced when students try to persuade others using evidence to justify their own models (Lee and Kim 2014).

In Group 6, critical monitoring took place mainly in the third lesson, which involved the construction of a final comprehensive model of the circulatory system. Their critical monitoring was not a one-time event; rather, it was produced iteratively and was influenced by interactions within the group. In the third lesson, the target model was a system model, which required the students to coherently connect sub-models, such as the systemic circulation, pulmonary circulation, gas exchange in each organ and muscle, and so on. In other words, this lesson required comprehensive thinking skills. The students needed metacognitive competencies in order to evaluate and modify the sub-models. Furthermore, making coherent connections among sub-models required evaluation and modification processes (Verhoeff et al. 2008). Consequently, the metacognitive activity (MA) category predominated in this lesson. The students constructed models by integrating information regarding structure, function or action, and the causal mechanisms related to blood circulation. They also made in-depth inferences during the processes of model evaluation, revision, and elaboration (Gobert and Pallant 2004). This finding showed that students actively participated in an argumentative practice that generated, evaluated, and modified their model repeatedly.

Episode 4 of the third lesson is shown in Table 10. It demonstrates the process of modeling systemic circulation. The heart-leg muscle circuit and the cyclical process involving model generation, evaluation, and modification (GEM) are well illustrated. Student A raised a question when she realized that the blood circulation diagram drawn by Group 6 members went contrary to her own knowledge, and she produced the statement associated with DLA resolve discrepancies in knowledge (AQ-b), raising problems she saw in the diagrams that they had drawn so far (Line 1). Her monitoring question seemed to stimulate an evaluation of the existing model, but the other students did not agree with A's opinion (Lines 2 and 3). Hence, student A qualified her previous statement in greater detail and evaluated the model as follows: "There is no superior vena cava that connects the leg muscle and the heart" (Line 4). This statement associated with DLA having the argumentative aim of persuading, since it was an evidence-based logical explanation, and it enabled the other students to make sense of student A's previous question.

Although students $\mathrm{C}$ and $\mathrm{D}$ eventually came to recognize the problem, they initially decided to ignore it and suggested that they either continue drawing or connect the wrong lines (Lines 7 and 8). Against these responses, student A showed evaluate own idea (MA-a) by pointing out that the vessel should have been drawn on both sides (Line 9). This statement associated with DLA functioned not only to evaluate the existing idea but also to provide a solution. She applied the concept of the branched systemic circulation to the model: "Leg muscle and brain circuit have different veins." She suggested the "warrant," which was the component of argumentation, as identified by Toulmin (1958), because she not only insisted that the existing diagram was wrong, but she also gave corresponding reasons for her statement. Her attempt showed argumentative discourse through persuading, and the group model was consequently modified and developed through this process.

Student A's statements, which aimed to modify the model through suggesting the warrant, enhanced the understanding and participation of the other group members. This finding was detected in the following statement associated with DLA: Students C and D evaluated the modified model by producing evaluate other's idea (NE-a) and request information about mechanism (AQ-a), respectively (Lines 10 and 11). Metacognitive thinking skills, based on an understanding of the existing ideas, are required in order to evaluate the model or the others' opinions (Lee and Kim 2014). In this regard, students C and D showed argumentative discourse sense-making in relation to their evaluation of A's revised model (Line 9). This finding indicated that although student D was classified as a surface learner, she was still capable of showing a high level of cognitive thinking skills.

Although both students C and D presented the statements associated with DLA evaluating student A's model, the epistemic criteria for evaluating the model were different for each student. For instance, student D criticized student A's idea by focusing on a superficial component in the blood circulation diagram, whereas student $\mathrm{C}$ evaluated student A's model, in terms of sense-making, when she found that the lines were connected incorrectly in student A's model, contrary to the principle she already knew. Pluta et al. (2011) stressed that evaluating models using epistemic criteria is a critical scientific practice, and they classified the epistemic criteria related to an explanatory model into primary and secondary criteria. In this respect, student $\mathrm{C}$ presented the primary epistemic criteria of 
Table 10 Episode 4 in lesson 3 (Systemic circulation: heart-leg muscle circuit)

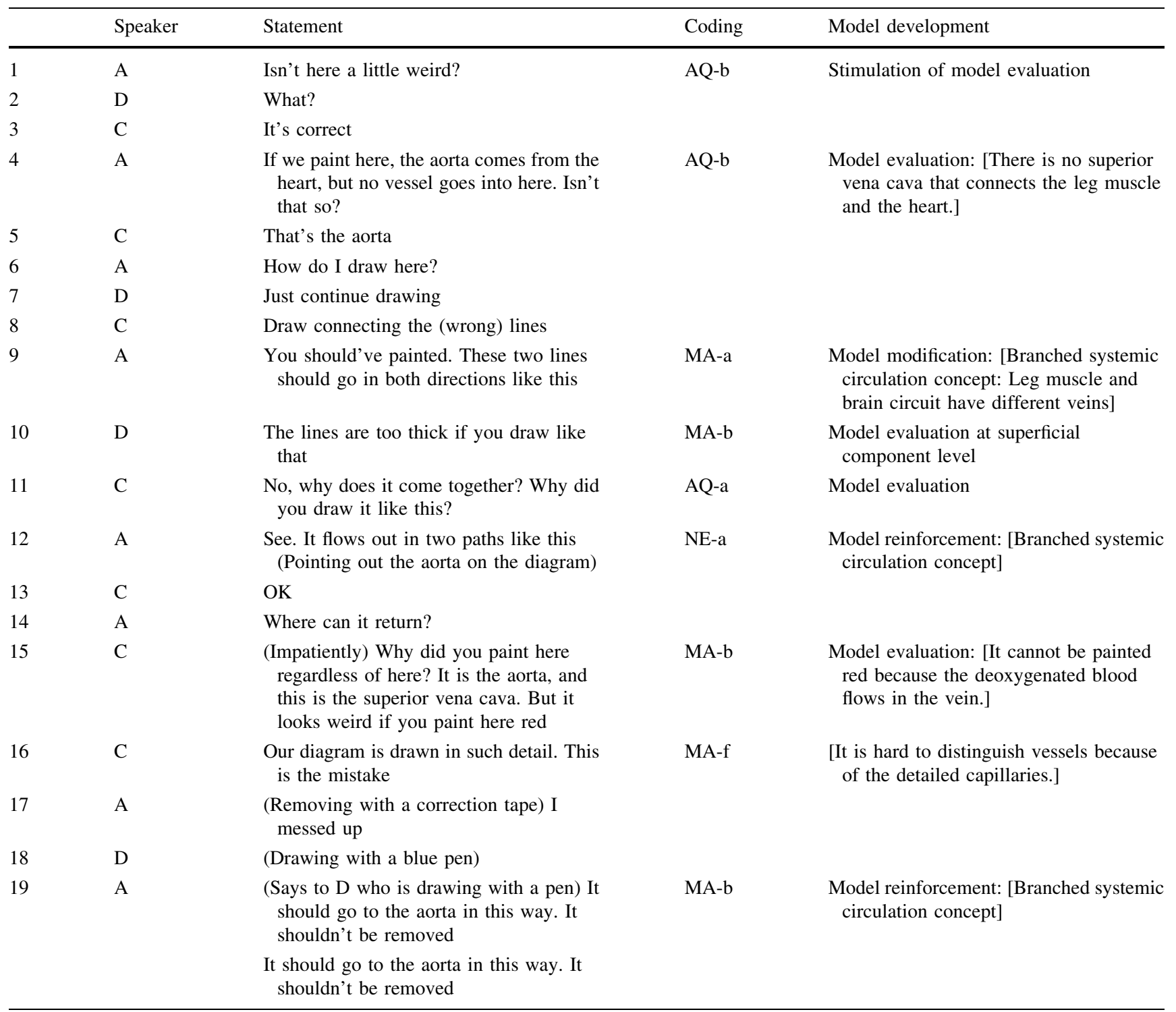

$A Q-a$ request information about mechanism, $A Q-b$ resolve discrepancies in knowledge, $N E-a$ focus on explanation of the mechanism, $M A-a$ evaluate own idea, $M A-b$ evaluate other's idea, $M A-f$ reflect on lack of understanding

sense-making, which was intended to improve the accuracy of the model and come close to its true nature. Therefore, she used a higher level of epistemic criteria compared to student D, who employed secondary epistemic criteria, such as the model constituent, for her communication of the idea.

Student A reinforced and articulated the previous model in order to argue against the evaluations made by students $\mathrm{C}$ and D (Lines 10 and 11) and to justify her revised model (Line 12). She utilized the statement associated with DLA, focus on explanation of the mechanism (NE-a), which was based on an explanation about structural features, and she pointed out two vessels stretching, respectively, to the brain and the leg in the blood circulation diagram. Her intention was to help others to understand the branched systemic circulation model, and this attempt revealed the argumentative discourse persuading. Student $\mathrm{C}$ understood student A's idea and agreed with it (Line 13). Although the rest of them did not provide verbal responses, we assume these students showed tacit consent since they neither criticized nor refuted student A's opinion.

Even though she agreed with the concept of a branched systemic circulation, as suggested by student $\mathrm{A}$, student $\mathrm{C}$ criticized student A's idea concerning the painting of the oxygenated and deoxygenated blood. She opined, "It cannot be painted red because deoxygenated blood flows in 
the vein," thus showing the statement associated with DLA, evaluate other's idea (MA-b) (Line 15). Her evaluation of the model was based on a logical causal relationship. Student $\mathrm{C}$ realized that the other students did not notice the problem that drawing too many capillaries had hindered the ability to distinguish between vessels. She then rephrased her previous statement in order to enhance sense-making (Line 16). This statement was categorized as the statement associated with DLA, reflect on lack of understanding (MA-f), which provided other students with the opportunity to reflect on their own modeling practice and enabled them to construct a better model. As a result, student A's statement and performance reported in Line 17 showed that she understood the problems raised by student C. Student D also presented with understanding and modified the existing model by correcting the wrong part using a blue pen (Line 18).

In addition, approach to task (AT), as proposed by Chin and Brown (2000), was well illustrated in student C's practice. According to Chin and Brown (2000), deep learners persist in following up on an idea with some sustained interest before moving to another one when they are engaged in the task at hand. In illustration of this, student $\mathrm{C}$ in this study did not produce the statement associated with DLA in a single discourse sequence but instead showed consistent interest in her topic by continuing to criticize others' ideas and trying to persuade others to accept hers. Accordingly, the characteristics of statements associated with DLA approach to task did not appear in a particular statement, but several statements produced in an episode should be consecutively examined for detecting statement associated with DLA approach to task. Hence, it was not counted as a statement in the present study.

The findings showed that critical monitoring enabled the students to evaluate and modify the model, and cognitive scaffolding and other forms of monitoring also emerged in the course of the case, as shown in Table 10. Critical monitoring also involves the goals of argumentative discourse, such as persuading and sense-making, and the students showed active participation in the epistemic practice of science learning. Several researchers have pointed out that modeling practice is based on argumentation (Böttcher and Meisert 2011; Mendonça and Justi 2013; Passmore and Svoboda 2012). Our results supported their assertions. The group model was developed by successive evaluations and modifications of the model through argumentative interactions. The cognitive participation and understanding of group members were enhanced accordingly.

\section{Discussion}

In this study, we explored how statements associated with DLA contribute to cognitive collaboration in group modeling related to blood circulation. To that end, we presented how statements associated with DLA affected the group dynamics during the group modeling process and how the group dynamics influenced cognitive collaboration and the development of the group model. To address these research questions, we viewed the group modeling as social learning in terms of the sociocognitive perspectives. This study demonstrated that individual learning approaches not only affected individual learning but also influenced the group modeling learning process. We think that a proper understanding of the impact of individual learning approaches will have a synergistic effect on the group modeling process. We hope our findings will lead to practical educational insights for educators seeking to use group modeling-based lessons.

The group dynamics triggered by statements associated with DLA were examined through the modeling process, proceeding through the model generation, elaboration, evaluation, and modification phases. In the model generation phase, student A showed skill in initiating the model generation by employing the statement associated with DLA concerning a focus on the principle of blood circulation. This provided scaffolding to student $\mathrm{C}$, who generated another sub-model-pulmonary circulation. In the model elaboration phase, statements associated with DLA elements, such as request information about mechanism (AQ-a) and resolve discrepancies in knowledge (AQ-b), provided students with metacognitive scaffolding and enabled them to show their deep cognitive participation. Moreover, statements associated with DLA elements, such as asking questions (AQ) or metacognitive activity (MA), enabled the students to monitor others' models or ideas critically, which showed that active cognitive interaction took place within the group. Although the students' reactions to statements associated with DLA did not always lead to deep cognitive participation, the elaborated and revised group models were constructed and shared between the group members through a series of cognitive interactions with the aim of argumentative discourse, such as sense-making, articulating, and persuading. Finally, the cognitive scaffolding and critical monitoring triggered by statements associated with DLA stimulated other students' cognitive participation, and a group dynamic emerged during this process, with group models developing accordingly. 
Deep Learning Approaches in the Group Modeling Learning Process

The findings of the current study partly support previous claims that the learning approach is the key frame that distinguishes the differences in students' learning strategies and is consistent over different situations as a learning orientation (e.g., BouJaoude 1992; Entwistle 1981; Entwistle and Ramsden 1983; Schmeck 1988). A study carried out by BouJaoude (1992) on the learning approaches of high school students explored the relationships between learning approaches and other factors, such as preconception, attitudes toward chemistry, and misconception testing. BouJaoude analyzed the differences in students' responses depending on their learning approaches. Based on the results, deep learners were more likely to answer correctly than surface learners. The former also tended to connect meaningful information to their own knowledge and to apply such information to new situations. In the same manner, students $\mathrm{A}$ and $\mathrm{C}$ in our study also consistently demonstrated deep learning approaches through the first to the third lesson. They participated in the cognitive process of group modeling by applying previous knowledge to current learning in a meaningful way.

With regard to learning approaches, the findings also strongly supported an idea that differed from that claimed in previous studies (e.g., Marton 1983; Ramsden 1992); that is, students' adoption of either a deep or surface learning approach depends on the particular context. Students $\mathrm{B}$ and $\mathrm{D}$, who are surface learners, showed little participation compared to low-achieving student $\mathrm{C}$, who had a deep learning approach to the modeling processes in the first and second lessons, and they hardly showed statements associated with DLA in the first two lessons. However, they performed quite differently in the third lesson, even showing similar frequencies of statements associated with DLA to those produced by students A and C; this can be seen in Episodes 3 and 4 in lesson 3. This finding showed that students' learning approaches can be transformed in a group modeling context.

The learning context of group modeling might serve a role in the transformation of students B and D, and deep learners' performance led to a change of group norms in interaction during group modeling. In fact, students B and $\mathrm{D}$, who were categorized as surface learners, were stimulated by students $\mathrm{A}$ and $\mathrm{C}$, who showed consistent cognitive participation with statements associated with DLA. This finding is similar to the assertions made by Marton (1983) and Ramsden (1992). These researchers claimed that the learning context plays an important role in employing different types of learning approaches and that learning approaches should be viewed as a response to the situation rather than as a stable characteristic of the students. In this regard, consistent cognitive collaborations, such as cognitive scaffolding and critical monitoring, had a significant influence on the changes in the learning approach exhibited by students B and D.

The above-mentioned finding supports our assertion that group modeling should be viewed as a social learning practice from a sociocognitive perspective. Chin and Brown (2000) explored deep learning approaches by focusing on the individual engaged in learning and showed that deep learners explained and raised questions about the mechanisms or causal relationships of scientific phenomena and evaluated their own or others' ideas when noticing discrepancies in knowledge. However, the present study went further than Chin and Brown's work in finding that an individual's learning approach is stable over diverse situations and can contribute to collaborative modeling-based learning by affecting the learning approaches of others. Some students' statements associated with DLA created the context, such as cognitive scaffolding and critical monitoring, for other students and enabled them to also produce statements associated with DLA. Accordingly, students' cognitive interactions influenced model development processes, such as model generation, evaluation, elaboration, and modification.

\section{Experience Caused by the Statements Associated with DLA in Group Modeling}

This study supported the findings of previous studies (e.g., Böttcher and Meisert 2011; Mendonça and Justi 2013; Passmore and Svoboda 2012), which revealed that the modeling process is based on argumentation since the participants' statements associated with DLA affected the argumentative interaction in the group modeling process in this study. In addition, our study showed that the statements associated with DLA might function as the critical factor enhancing argumentative interactions. For instance, the statements associated with DLA that initiated the model generation phase, focus on explanation of the mechanism (NE-a), was produced by articulating the key principle of the target phenomena for enhancing others' sense-making. The deep approach questions regarding request information about mechanism (AQ-a) raised in the model elaboration phase were intended to articulate the sense-making of the target phenomena. Moreover, one student tried to persuade others using sense-making when she found the gap between her own and others' ideas, and the deep approach questions concerning resolve discrepancies in knowledge (AQ-b) were shown at that time. In addition, the statements associated with DLA related to asking questions (AQ) or metacognitive activity (MA) emerged with the purpose of persuading others in the model evaluation and modification phases. 
The students in Group 6 participated in the argumentative discourse in terms of assertions and justifications based on evidence with aims including sense-making, articulating, and persuading via the statements associated with DLA. Through organizing their ideas, generating hypotheses, and constructing arguments based on the evidence, these students experienced the epistemic practice of science learning during group modeling processes. In the same manner, Windschitl et al. (2008) claimed that modelbased inquiry supported the five epistemic features of scientific knowledge: It is testable, revisable, explanatory, conjectural, and generative. Some previous studies explored secondary students' modeling practice with the help of the teacher (e.g., Louca et al. 2011; Mendonça and Justi 2013; Núñez-Oveido et al. 2008; Passmore and Svoboda 2012) and investigated the epistemic value of modeling by only focusing on the model evaluation phase (e.g., Lee and Kim 2014; Nelson and Davis 2012; Penner et al. 1997). However, our study findings have the possibility of reinforcing the epistemic value of group modeling practice by exploring the students' argumentative interaction in all modeling phases such as model generation, elaboration, evaluation, and modification.

\section{Implications}

Studies on learning approaches have presented students' epistemology concerning science (Chiou et al. 2013). Individual students' learning approaches represent a learning orientation that reflects their motivations, beliefs, attitudes, previous knowledge, and learning conceptions (Entwistle 1981). However, the learning approach will emerge in different forms according to institutional factors (Biggs 1993). In this sense, a learning approach can be viewed as an individual epistemic belief or learning tendency related to science learning. The individual student's epistemic belief could affect his or her learning processes or outcomes (Songer and Linn 1991). As can be seen in our study, individual learners' learning approaches can enlarge their own ideas, as well as those of others, as the cognitive foothold or the link during the group modeling process, and modeling practice as social learning was identified in our participants.

These findings will raise suggestions for science teachers concerning the teaching and learning environment in science lessons. First, teachers need to identify the students' learning approaches and their understanding of learning. Second, teachers should provide a learning environment that encourages students to determine the deep learning approaches during modeling practices and should consider students' individual characteristics related to learning motivations and strategies, while they are learning in groups. In addition, the teacher needs to explicitly instruct students to make claims and justifications based on the evidence, which are argumentative discourse features, in order to lead a successful group modeling lesson. In this way, cognitive collaborations among students will be activated, while they are involved in group modeling.

In order to explore the cognitive collaboration in group modeling processes, we conducted a case study on a group of four students in a science lesson taught by a teacher. Therefore, the model development process concerning group dynamics caused by statements associated with DLA cannot be generalized at present. However, in order to improve trustworthiness, our study undertook a variety of careful procedures when it came to data collection. We collected evidence from multiple sources, including transcripts, blood circulation diagrams, students' work sheets, questionnaires, and researchers' journals, and collaborated with the coauthors and the teacher to thoroughly examine the students' class discourses, which employed the developed program regarding blood circulation for group modeling.

Although we found that statements associated with DLA could have a positive effect on cognitive collaboration during a group modeling process, which is educationally significant, our study does have the limitation that it cannot be generalized; we only analyzed the case of one small group in a certain context. In order to better support our results, it is necessary to analyze in a follow-up study the modeling process of eight other groups that were not analyzed in this study. This will not only contribute further evidence to our results, which showed that statements associated with DLA could have a positive effect on cognitive collaboration and model development in a small group, but also explore synergistic effects or relationships between the statements associated with DLA and various contexts.

The statements associated with DLA stimulated a series of cognitive reasoning processes during the group modeling. However, it should be noted that not all statements associated with DLA led to reasoning processes and model development. Further research should explore how the learning environment influenced the statements associated with DLA and subsequent cognitive collaboration in group modeling. In addition, longitudinal research concerning the effects of group modeling lessons on students' learning approaches could be carried out with the aim of identifying whether students apply the same methods in other disciplines. These studies would support the students' epistemic experiences of modeling in an environment in which individual characteristics, such as motivation and strategies, used in the approaches to learning science were appropriately considered. 
Acknowledgments This work was supported by the National Research Foundation of Korea Grant funded by the Korean Government (NRF-2012S1A5A2A03034667). The opinions expressed in this work are those of the authors and not necessarily those of the NRF.

Open Access This article is distributed under the terms of the Creative Commons Attribution License which permits any use, distribution, and reproduction in any medium, provided the original author(s) and the source are credited.

\section{References}

Acher A, Arcá M, Sanmarti N (2007) Modeling as a teaching learning process for understanding materials: a case study in primary education. Sci Educ 91(3):398-418

Achieve, Inc. on behalf of the twenty-six states and partners that collaborated on the NGSS (2013). Next Generation Science Standards. Achieve, Inc. on behalf of the twenty-six states and partners that collaborated on the NGSS

Berland LK, Reiser BJ (2009) Making sense of argumentation and explanation. Sci Educ 93(1):26-55

Berland LK, Reiser BJ (2011) Classroom communities' adaptation of the practice of scientific argumentation. Sci Educ 95(2):191-216

Bianchini JA (1997) Where knowledge construction, equity, and context intersect: student learning of science in small groups. Journal of Research in Science Teaching 34(10):1039-1065

Biggs J (1993) What do inventories of students' learning processes really measure? A theoretical review and clarification. Br J Educ Psychol 63(1):3-19

Böttcher F, Meisert A (2011) Argumentation in science education: a model-based framework. Sci \& Educ 20(2):103-140

BouJaoude SB (1992) The relationship between students' learning strategies and the change in their misunderstandings during a high school chemistry course. Journal of Research in Science Teaching 29(7):687-699

Buckley BC (2000) Interactive multimedia and model-based learning in biology. Int J Sci Educ 22(9):895-935

Cano F (2005) Epistemological beliefs and approaches to learning: their change through secondary school and their influence on academic performance. Br J Educ Psychol 75(2):203-221

Case J, Gunstone R (2002) Metacognitive development as a shift in approach to learning: an in-depth study. Stud High Educ 27(4): $459-470$

Cavallo AMN, Schafer LE (1994) Relationships between students' meaningful learning orientation and their understanding of genetics topics. Journal of Research in Science Teaching 31(4):393-418

Chi MTH (2005) Commonsense conceptions of emergent processes: why some misconceptions are robust. The Journal of the Learning Sciences 14(2):161-199

Chi MTH, Slotta JD, de Leeuw N (1994) Eliciting things to processes: a theory of conceptual change for learning science concepts. Learning and Instruction 4(1):27-43

Chin C, Brown DE (2000) Learning in science: a comparison of deep and surface approaches. Journal of Research in Science Teaching 37(2):109-138

Chin C, Chia LG (2004) Problem-based learning: using students' questions to drive knowledge construction. Sci Educ 88(5):707727

Chiou GL, Liang JC, Tsai CC (2012) Undergraduate students' conceptions of and approaches to learning in biology: a study of their structural models and gender differences. Int $\mathrm{J}$ Sci Educ 34(2):167-195

Chiou GL, Lee MH, Tsai CC (2013) High school students' approaches to learning physics with relationship to epistemic views on physics and conceptions of learning physics. Research in Science \& Technological Education 31(1):1-15

Clement JJ (2008) Student/teacher co-construction of visualizable models in large group discussion. In: Clement JJ, Rea-Ramirez MA (eds) Model based learning and instruction in science. Springer, Dordrecht, pp 11-22

Denzin NK, Lincoln YS (2005) The sage handbook of qualitative research. Sage Publications, Thousand Oaks

Driver R, Newton P, Osborne J (2000) Establishing the norms of scientific argumentation in classrooms. Sci Educ 84(3):287-312

Duit R (1991) On the role of analogies and metaphors in learning science. Sci Educ 75(6):649-672

Duschl RA, Schweingruber HA, Shouse AW (eds) (2007) Taking science to school: learning and teaching science in grades K-8. National Academies Press, Washington, DC

Entwistle NJ (1981) Styles of learning and teaching. Wiley, Chichester

Entwistle NJ, Ramsden P (1983) Understanding student learning. Croom Helm, London

Giere RN (1999) Using models to represent reality. In: Magnani L, Nersessian NJ, Thagard P (eds) Model-based reasoning in scientific discovery. Kluwer Academic, Dordrecht, pp 41-57

Gilbert JK, Boulter CJ, Elmer R (2000) Positioning models in science education and in design and technology education. In: Gilbert JK, Boulter CJ (eds) Developing models in science education. Kluwer Academic, Dordrecht, pp 3-17

Gobert JD, Pallant A (2004) Fostering students' epistemologies of models via authentic model-based tasks. J Sci Educ Technol 13(1):7-22

Grosslight L, Unger C, Jay E (1991) Understanding models and their use in science: conceptions of middle and high school students and experts. Journal of Research in Science Teaching 28(9):799-822

Harrison AG, Treagust DF (2000) A typology of school science models. Int J Sci Educ 22(9):1011-1026

Hogan K, Pressley M (1997) Scaffolding student learning: instructional approaches and issues. Brookline Books, Cambridge

Jiménez-Aleixandre MP, Erduran S (2008) Argumentation in science education: an overview. In: Erduran S, Jiménez-Aleixandre MP (eds) Argumentation in science education: perspectives from classroom-based research. Springer, Dordrecht, pp 3-25

Justi RS, Gilbert JK (2002) Modelling, teachers' views on the nature of modelling, and implications for the education of modellers. Int J Sci Educ 24(4):369-387

Kim MC, Hannafin MJ (2011) Scaffolding problem in technologyenhanced learning environments (TELEs): bridging research and theory with practice. Comput Educ 56(2):403-417

Krajcik J, Merritt J (2012) Engaging students in scientific practices: What does constructing and revising models look like in the science classroom? Science Teacher 79(3):38-41

Kyza EA, Constantinou CP, Spanoudis G (2011) Sixth Graders' Coconstruction of Explanations of a Disturbance in an Ecosystem: exploring relationships between grouping, reflective scaffolding, and evidence-based explanations. Int J Sci Educ 33(18):2489-2525

Lee S, Kim HB (2014) Exploring secondary students' epistemological features depending on the evaluation levels of the group model on blood circulation. Sci \& Educ 23(5):1075-1099

Lee MH, Johanson RE, Tsai CC (2008) Exploring Taiwanese high school students' conceptions of and approaches to learning science through a structural equation modeling analysis. Sci Educ 92(2): 191-220

Lehrer R, Schauble L (2012) Seeding evolutionary thinking by engaging children in modeling its foundations. Sci Educ 96(4):701-724

Louca LT, Zacharia ZC, Constantinou PC (2011) In quest of productive modeling-based learning discourse in elementary 
school science. Journal of Research in Science Teaching 48(8):919-951

Marton F (1983) Beyond individual differences. Educational Psychology 3(3-4):289-303

Mendonça PCC, Justi R (2013) The relationships between modelling and argumentation from the perspective of the model of modelling diagram. Int J Sci Educ 35(14):2407-2434

Merriam SB (1988) Case study research in education. Jossey-Bass, San Francisco

Morrison M, Morgan MS (1999) Models as mediating instruments. In: Morgan MS, Morrison M (eds) Models as mediators: perspectives on natural and social science. Cambridge University Press, Cambridge, pp 10-37

Nelson MM, Davis EA (2012) Preservice Elementary Teachers' Evaluations of Elementary Students' Scientific Models: an aspect of pedagogical content knowledge for scientific modeling. Int J Sci Educ 34(12):1931-1959

Nersessian NJ (1999) Model-based reasoning in conceptual change. In: Magnani L, Nersessian NJ, Thagard P (eds) Model-based reasoning in scientific discovery. Kluwer Academic, Dordrecht, pp 5-22

Núñez-Oveido MC, Clement J, Rea-Ramirez MA (2008) Developing Complex Mental Models in Biology Through Model Evolution. In: Clement JJ, Rea-Ramirez MA (eds) Model based learning and instruction in science. Springer, Dordrecht, pp 173-193

Odenbaugh J (2005) Idealized, inaccurate but successful: a pragmatic approach to evaluating models in theoretical ecology. Biol Philos 20(2-3):231-255

Oliveira AW, Sadler TD (2008) Interactive patterns and conceptual convergence during student collaborations in science. Journal of Research in Science Teaching 45(5):634-658

Passmore CM, Stewart J (2002) A modeling approach to teaching evolutionary biology in high school. Journal of Research in science teaching 39(3):185-204

Passmore C, Svoboda J (2012) Exploring opportunities for argumentation in modelling classrooms. Int J Sci Educ 34(10):1535-1554

Patton M (1987) How to use qualitative methods in evaluation. Sage Publications, Newbury Park

Penner DE, Giles ND, Lehrer R, Schauble L (1997) Building functional models: designing an elbow. Journal of Research in Science Teaching 34(2):125-143

Pluta WJ, Chinn CA, Duncan RG (2011) Learners' epistemic criteria for good scientific models. Journal of Research in Science Teaching 48(5):486-511

Ramsden P (1992) Learning to teach in higher education. Routledge, New York

Rea-Ramirez MA, Clement J, Núñez-Oveido MC (2008) An instructional model derived from model construction and criticism theory. In: Clement JJ, Rea-Ramirez MA (eds) Model based learning and instruction in science. Springer, Dordrecht, pp 23-43

Roschelle J, Teasley SD (1995) The construction of shared knowledge in collaborative problem solving. In: O'Malley CE (ed) Computer-supported collaborative learning. Springer, Berlin, pp 69-97

Säljö R (1979) Learning about learning. High Educ 8(4):443-451

Schmeck RR (1988) An introduction to strategies and styles of learning. In: Schmeck RR (ed) Learning strategies and learning styles. Plenum, New York, pp 3-19

Schwarz CV, White BY (2005) Metamodelling knowledge: developing students' understanding of scientific modelling. Cognition and Instruction 23(2):165-205

Schwarz CV, Reiser BJ, Davis EA, Kenyon L, Achér A, Fortus D, Shwartz Y, Hug B, Krajcik J (2009) Developing a learning progression for scientific modeling: making scientific modeling accessible and meaningful for learners. Journal of Research in Science Teaching 46(6):632-654

Songer NB, Linn MC (1991) How do students' views of science influence knowledge integration? Journal of Research in Science Teaching 28(9):761-784

Stewart J, Dale M (1989) High school students' understanding of chromosome/gene behaviour during meiosis. Sci Educ 73(4):501-521

Svoboda J, Passmore C (2013) The strategies of modeling in biology education. Sci \& Educ 22(1):119-142

Toulmin SE (1958) The use of argument. Cambridge University Press, Cambridge

Treagust DF, Chittleborough G, Mamiala TL (2002) Students' understanding of the role of scientific models in learning science. Int J Sci Educ 24(4):357-368

Verhoeff RP, Waarlo AJ, Boersma KT (2008) Systems modelling and the development of coherent understanding of cell biology. Int $\mathrm{J}$ Sci Educ 30(4):543-568

Vygotsky LS (1978) Mind and society. The development of higher psychological processes. Harvard University Press, Cambridge. MA

Wells M, Hestenes D, Swackhamer G (1995) A modeling method for high school physics instruction. Am J Phys 63(7):606-620

Windschitl M, Thompson J, Braaten M (2008) Beyond the scientific method: model-based inquiry as a new paradigm of preference for school science investigations. Sci Educ 92(5):941-967

Wood D, Bruner JS, Ross G (1976) The role of tutoring in problem solving. Journal of Child Psychology Psychiatry 17:89-100

Yin R (1989) Case study research: design and methods. Sage Publications, Newburry Park 